\title{
Establishment of an interdisciplinary board for bone and joint infections
}

\author{
Christina Otto-Lambertz ${ }^{1}$ (i) $\cdot$ Ayla Yagdiran ${ }^{1}$ (i) $\cdot$ Kirsten Schmidt-Hellerau ${ }^{2}$ (i) $\cdot$ Charlotte Meyer-Schwickerath $^{2}$ (D) \\ Peer Eysel ${ }^{1}$ (D) Norma Jung $^{2}$ (i)
}

Received: 7 May 2021 / Accepted: 26 July 2021 / Published online: 2 August 2021

(c) The Author(s) 2021

\begin{abstract}
Purpose The incidence of bone and joint infections is increasing while their treatment remains a challenge. Although guidelines and recommendations exist, evidence is often lacking and treatment complicated by complex clinical presentations and therapeutic options. Interdisciplinary boards shown to improve management of other diseases, seem potentially helpful. We describe the establishment of an osteomyelitis board to show the existing demand for such a platform.

Methods All patients discussed in the board for bone and joint infections between October 2014 and September 2020 were included in this retrospective study. Data were extracted from patient records and analyzed descriptively.

Results A total of 851 requests related to 563 patients were discussed in the board during the study period. After a run-in period of 3 years, a stable number of cases ( $>170 /$ year) were discussed, submitted by nearly all hospital departments (22 of 25). Recommendations were mainly related to antibiotic treatment (43\%) and to diagnostics (24\%). Periprosthetic joint infections were the most frequent entity (33\%), followed by native vertebral osteomyelitis and other osteomyelitis. In $3 \%$ of requests, suspected infection could be excluded, in $7 \%$ further diagnostics were recommended to confirm or rule out infection. Conclusions A multidisciplinary board for bone and joint infections was successfully established, potentially serving as a template for further boards. Recommendations were mainly related to antibiotic treatment and further diagnostics, highlighting the need for interdisciplinary discussion to individualize and optimize treatment plans based on guidelines. Further research in needed to evaluate impact on morbidity, mortality and costs.
\end{abstract}

Keywords Bone and joint infection · Interdisciplinary board · Periprosthetic joint infection · Vertebral osteomyelitis · Osteomyelitis · Foreign material-associated infection

\section{Introduction}

The number of bone and joint infections is increasing [1,2], which is thought to be due to an increase in predisposing factors (e.g. diabetes mellitus [3] and an aging population [4]), of medical invasive procedures and of surgical treatment of degenerative bone and joint changes and fractures, often including incorporation of foreign material.

Christina Otto-Lambertz

christina.otto-lambertz@uk-koeln.de

1 Department of Orthopedics and Trauma Surgery, Medical Faculty, University Hospital of Cologne, University of Cologne, Cologne, Germany

2 Department I of Internal Medicine, Medical Faculty, University Hospital of Cologne, University of Cologne, Cologne, Germany
Diagnosis and therapy of bone and joint infections are multi-faceted and complex. Infections include septic arthritis, osteomyelitis of the long bones and vertebral osteomyelitis as well as fracture-related infections, periprosthetic infections and other foreign material-associated bone infections. Diagnosing bone and joint infections is often difficult even though diagnostic criteria have been published in international guidelines [5-12]. Common diagnostic challenges are antibiotic treatment before proper diagnostics, lack of relevant samples (e.g. superficial swipes instead of bone specimen) and discrimination between relevant pathogens and contaminants.

The building blocks of treatment come from both internal medicine and surgical disciplines. Surgical therapy is complex and antiinfective therapy often of long duration. Therapeutic options are time- and resource-consuming [13] and approaches often not evidence based. In addition to surgical 
interventions such as classical debridement, interventional approaches such as vascular recanalization and interventional pathogen retrieval (e.g. CT-guided puncture) are often required. Therefore, several disciplines are involved in the treatment of complicated infections and communication between them often poses a challenge. In the context of oncological diseases, interdisciplinary boards have already been implemented for many years [14] and are an integral part of certified cancer centers [15]. In infectious diseases (ID), interdisciplinary discussion in form of an endocarditis board has been shown to lead to optimization of treatment processes. As shown by Camou et al., a weekly board meeting facilitates following official guidelines while adapting them to the individual circumstances, leading to improved clinical outcomes in the treatment of endocarditis [16].

Regarding this previous evidence, an interdisciplinary approach including orthopedic and trauma surgeons, ID specialists, radiologists and microbiologists seems desirable for the optimal management of complex bone and joint infections, but this is rarely described. In France, for example, it is mandatory that complex bone and joint infections are treated in specialized centers with regular interdisciplinary meetings [17-19].

To meet this assumed need, an interdisciplinary weekly board for bone and joint infections (osteomyelitis board $=\mathrm{OMB}$ ) was implemented in a tertiary care hospital in Germany in 2014. The board consists of a weekly meeting of an ID specialist, orthopedic and trauma surgeon, microbiologist and radiologist.

The aim of this study was to describe the establishment of an interdisciplinary osteomyelitis board, the number and nature of requests to show the existing demand for such a platform and the type of recommendations made.

\section{Materials and methods}

\section{Study design and setting}

A weekly multidisciplinary $\mathrm{OMB}$ was implemented in a tertiary care hospital, a 1430 bed facility treating 58,400 in-patients per year (average 2014-2020). Patients with suspected or proven bone and/or joint infections could be registered for discussion via the electronic health record. All patients discussed in the OMB between October 2014 and September 2020 were included in our retrospective study.

\section{Data collection, variables and statistics}

Data were extracted from the written request and recommendation forms of the OMB in the electronic health record, anonymized and entered using Microsoft Excel 2010 software.
Recorded were the number of OMB requests, number of requests per patient, requesting departments, age and sex of patients. Further, the content of requests and recommendations was recorded and assigned to different diagnostic and therapeutic categories for analysis. In case of more than one OMB consultation for the same patient during the same inpatient stay, all consultations were analyzed.

Types of infection were classified as periprosthetic joint infection (PJI), other implant-associated bone infection, native vertebral osteomyelitis, other types of osteomyelitis and septic arthritis. Infections associated with internal plate and/or screw fixation were subsumed under "other implantassociated bone infections".

Data were analyzed descriptively using Microsoft Excel 2010. For categorical variables, absolute numbers and proportions were analyzed, and for continuous variables median and interquartile ranges were created. Figures were created by GraphPadPrism 9 software.

\section{Results}

A total of 851 requests related to 563 patients were discussed in the OMB during the survey period from October 2014 until September 2020. Bedside infectious disease (ID) consultations also took place in $323 / 563$ patients in addition to the OMB within 1 week in cases of particular complexity especially when the primary focus was unknown and bloodstream infection occurred.

The number of departments enrolling patients in the OMB increased from 13 different departments in the first year to 22 departments 6 years later (Fig. 1), corresponding to $88 \%$ (22 of 25 ) of departments involved in patient care at the university hospital. The total number of requests increased over a 3-year period until it reached a stable number of at least 170 requests per year (Fig. 2). One-third of patients $(32 \%, N=185)$ were discussed more than once, in few cases up to seven times (Table 1).

Requests mainly came from surgical $(N=716 ; 84 \%)$ and also from non-surgical departments $(N=135 ; 16 \%$; see Table 1$)$. Few requests $(6 \%, N=47)$ from surgical departments came from the outpatient clinics. Most requests were made by orthopedic surgery $(N=545 ; 64 \%)$, followed by trauma surgery $(N=82 ; 10 \%)$. Among the non-surgical departments, subspecialties of internal medicine [hematooncology/infectiology/immunology $(N=42 ; 5 \%)$; general medicine/nephrology/rheumatology $(N=38 ; 5 \%)]$ were the most frequent requestors (Table 1). Requests from surgical departments were more often related to antibiotic therapy only (46 versus $7 \%$ ) while colleagues from non-surgical departments asked more often for advice related to antibiotic and surgical treatment (66 versus $38 \%$ ). 


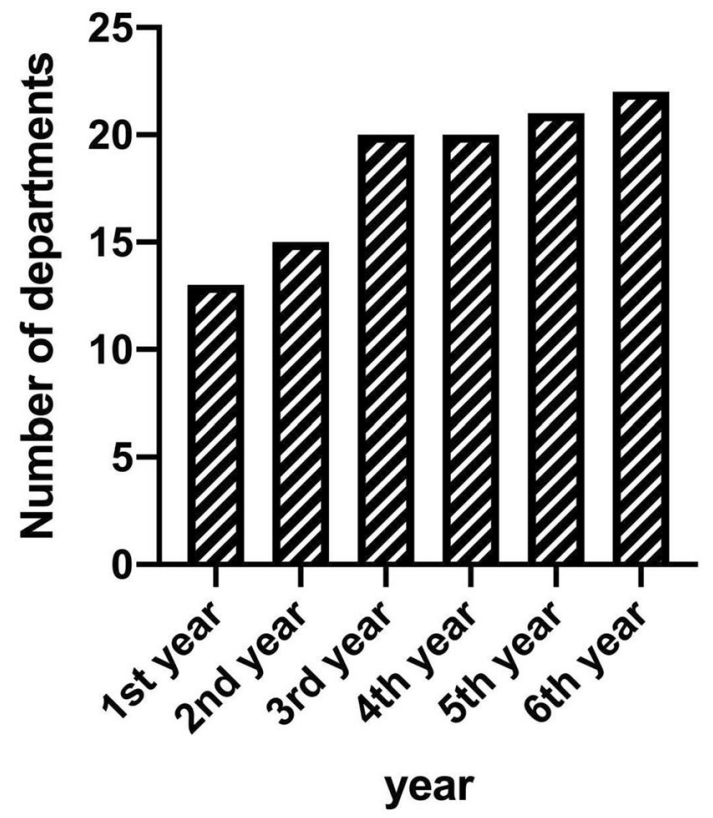

Fig. 1 Development of the number of departments enrolling patients in the OMB $(O M B$ osteomyelitis board). In the last year, cases were submitted by 22 of 25 departments involved in patient care at our university hospital

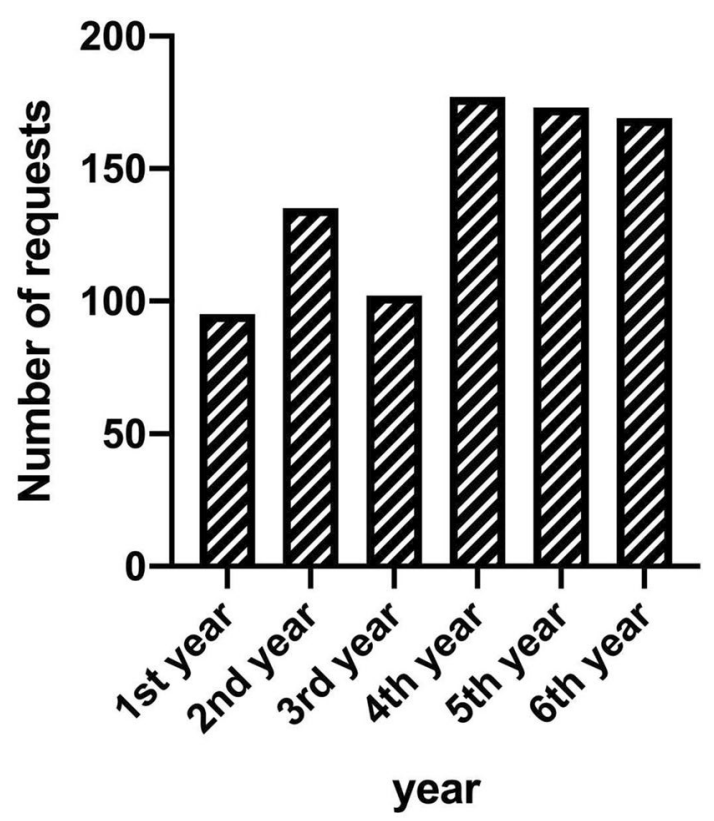

Fig. 2 Development of requests for the OMB over the years $(O M B$ osteomyelitis board). A continuous increase can be seen up to stablehigh numbers of about 170 cases/year

The 851 requests led to a total of 1394 recommendations (see Table 2). Over $43 \%$ of these recommendations were related to antibiotic therapy. This included recommendations regarding duration of therapy in $25 \%$ and a change from intravenous to oral treatment in $17 \%$ of all recommendations. Almost a quarter of all recommendations $(n=334,24 \%)$ were related to diagnostics, mainly imaging (including, e.g. MRI, CT and echocardiography), collection of material for microbiological diagnostics, consultations of other medical specialties and other examinations (for example, echocardiography or colonoscopy). In more than $16 \%(n=222)$ of the recommendations, surgery was recommended (mainly surgical revisions with debridement with or without removal/ change of foreign material). In only $2 \%$ of patients no change in the patient's therapeutic and diagnostic approach resulted from presentation to the OMB.

Among the 563 patients, 47 (8\%) presented with more than one focus of infection, mostly an additional bone or joint infection (see Table 3). Different infectious foci in one patient either occurred per continuitatem (e.g. osteomyelitis of tibia and soft tissue infection of lower leg) or via hematogenous dissemination (e.g. vertebral osteomyelitis and shoulder empyema). Bacteremia was detected in 19 patients, among these 6 patients suffered from endocarditis.

Over all, 900 suspected foci of infection were discussed. Of these foci, 28 were classified as non-infectious without indication for antiinfective treatment (in 12/28 a detected pathogen was assessed to be an irrelevant contaminant, in $9 / 28$ only clinical follow-up, $7 / 28$ further investigation to assess differential diagnosis). A further 67 of the 900 suspected foci of infection were evaluated to be possibly infectious, and additional diagnostics were recommended to either confirm or rule out infection. Periprosthetic joint infection $(N=294)$ was most frequent among the confirmed bone and joint-associated foci $(N=706 / 900)$ (Fig. 3) followed by surgical wound infections (70/900) and by other soft tissue infections (29/900).

$61(9 \%)$ patients presented to the OMB for interdisciplinary evaluation had a history of malignant tumors and 80 $(12 \%)$ of trauma in the area of infection.

\section{Discussion}

We describe the implementation, utilization and activities of an interdisciplinary board for bone and joint infections. The number of requests to the board shows a perceived need to discuss these cases, while an analysis of the recommendations made by the board showed that in almost all cases interdisciplinary discussion led to recommendations regarding additional diagnostics and/or changes in treatment, suggesting a potential impact on outcomes.

After an initial run-in period of 3 years, which is possibly due to an increasing awareness of the board in the different departments, the OMB seems well accepted with a now continuously high number of requests submitted by almost all departments of the university hospital. A similar run-in 
Table 1 Number of OMB requests and requesting departments; OMB: osteomyelitis board

\begin{tabular}{ll}
\hline Parameters & Number (\%) \\
\hline Number of patients & $563(100 \%)$ \\
Male & $329(58 \%)$ \\
Age [years] (median (IQR)) & $67(53-76)$ \\
Number of patients discussed & \\
Once & $378(67 \%)$ \\
Twice & $120(21 \%)$ \\
Three times & $42(7 \%)$ \\
$>=$ four times & $23(4 \%)$ \\
Total number of requests & $851(100 \%)$ \\
Requesting department & \\
Surgical & $716(84 \%)$ \\
Orthopaedics & $545(64 \%)$ \\
Trauma surgery & $82(10 \%)$ \\
Surgical outpatient department & $47(6 \%)$ \\
Anesthesia & $15(2 \%)$ \\
Vascular surgery & $7(1 \%)$ \\
Maxillofacial surgery & $7(1 \%)$ \\
Other (Cardiac surgery, Neurosurgery, Urology, Ear, nose and throat surgery, Visceral & $13(2 \%)$ \\
surgery, Peadiatric surgery & \\
Non-surgical & $135(16 \%)$ \\
Hemato-oncology, Infectiology, Immunology & $42(5 \%)$ \\
General medicine, Nephrology, Rheumatology & $38(5 \%)$ \\
Paediatrics/paediatric oncology & $17(2 \%)$ \\
Cardiology, Pneumology & $16(2 \%)$ \\
Dermatology & $15(2 \%)$ \\
Other (Neurology, Endocrinology, Palliative care, Psychology) & $7(1 \%)$ \\
&
\end{tabular}

period of up to 5 years was described by Rieg et al. for the initialization of an infectious disease consultation service at four university hospitals in Germany [20]. The continuously high numbers of request from almost all departments of our tertiary care facility show an existing demand for such a platform.

Diagnoses discussed in the OMB were mainly periprosthetic infections and osteomyelitis. Due to a significant increase of artificial joint implantations in recent years, a high number of periprosthetic infections were expected, as this is a typical complication of artificial joint implantation $[21,22]$. Vertebral osteomyelitis, known to have an increasing incidence over the last years [23, 24], was the second most frequently discussed diagnosis along with osteomyelitis of other bones [25]. The acceptance and regular use of the OMB for these types of infection indicate a perceived need for an interdisciplinary discussion of these complex cases.

The high number of board recommendations regarding changes in antibiotic treatment and/or treatment duration as well as at the number of suspected infectious foci that were evaluated to be non-infectious $(N=28 / 900)$ hint at a relevant impact of the OMB on quality and quantity of antibiotic treatment. This is in line with a survey from Switzerland investigating the activity and impact of an ID specialist in a septic orthopedic unit on antibiotic use and costs [26]. Here, a substantial decrease in antibiotic use and costs was shown without a concurrent increase of recurrent infections.

Bedside ID consultations took place in addition to the OMB presentations in cases of particular complexity. Extensive data are available for the benefit of ID consultation services especially in the context of $S$. aureus bloodstream infection and also from a growing number of studies showing a substantial role in surgical and medical wards [20, 27-31]. Of note, phone consultations do not seem to be equivalent to consultations with bedside examination of the patients. In a retrospective analysis, mortality for $S$. aureus bloodstream infection was almost double for phone consultations compared to bedside ID consultations [32]. Therefore, it seems unlikely that multidisciplinary board discussions for complex bone infections can substitute bedside ID consultation entirely, but multidisciplinary board discussion seems to be a reasonable complementary tool with first data suggesting a benefit. For vertebral osteomyelitis, Ntalos et al. preformed a retrospective pre-post intervention study comparing a single discipline approach with a weekly multidisciplinary 
Table 2 Characteristic of OMB recommendations $(\mathrm{OMB}$ : osteomyelitis board)

\begin{tabular}{|c|c|}
\hline Parameter & Number $(\%)$ \\
\hline Total number of recommendations & $1394(100 \%)$ \\
\hline Additional diagnostics & $334(24 \%)$ \\
\hline Allergy testing in case of suspected antibiotic allergy & $13(1 \%)$ \\
\hline Imaging & $117(8 \%)$ \\
\hline MRI & $66(5 \%)$ \\
\hline $\mathrm{CT}$ & $15(1 \%)$ \\
\hline X-ray & $20(1 \%)$ \\
\hline Other (PET-CT, FKDS, scinti, angio, sono) & $12(1 \%)$ \\
\hline Collection of additional materials for microbiological examination* & $68(5 \%)$ \\
\hline Blood culture & $37(3 \%)$ \\
\hline Consultation & $61(4 \%)$ \\
\hline Infectiology & $26(2 \%)$ \\
\hline Orthopedics/trauma surgery & $10(1 \%)$ \\
\hline Rheumatology & $5(0.4 \%)$ \\
\hline Other examinations & $70(5 \%)$ \\
\hline Echocardiography & $34(2 \%)$ \\
\hline Colonoscopy & $8(1 \%)$ \\
\hline Recommendations regarding antiinfective treatment & $599(43 \%)$ \\
\hline Change from IV to PO & $241(17 \%)$ \\
\hline Determination of treatment duration & $343(25 \%)$ \\
\hline Change of drug & $130(9 \%)$ \\
\hline Surgery (e.g. debridement, removal/change of foreign material) & $222(16 \%)$ \\
\hline $\begin{array}{l}\text { Intervention (e.g. interventional vascular recanalization, joint/pleura puncture, change of } \\
\text { catheters) }\end{array}$ & $18(1 \%)$ \\
\hline Follow up only (clinical/radiological) & $31(2 \%)$ \\
\hline Maintain previous procedure & $32(2 \%)$ \\
\hline $\begin{array}{l}\text { No initiation of antiinfective treatment recommended (e.g. pathogen is evaluated as contami- } \\
\text { nant) }\end{array}$ & $28(2 \%)$ \\
\hline
\end{tabular}

*For each (revision) surgery the collection of deep samples for microbiological and pathological examination was recommended, if possible infections conference [33]. Here, multidisciplinary conference led to significant changes in antiinfective and surgical treatment and reduced days of antibiotic treatment, while no differences were detected for in-hospital complications or total in-hospital stay.

Our study has several limitations. As it was performed in one German tertiary care centre, our results cannot be easily generalized and need to be validated for primary care hospitals and other countries. Due to our study design which focused on the implementation and activities of the $\mathrm{OMB}$, adherence to recommendations and the impact on outcome parameters as morbidity, mortality and cost savings could not be evaluated. Nevertheless, a main strength of our study is the detailed evaluation of the establishment of an interdisciplinary board for bone and joint infections showing an existing demand and offering precise descriptions of the activities, these key figures that may inform both planning of similar boards in other settings and of studies evaluating such boards.

\section{Conclusion}

Multidisciplinary boards have shown to be beneficial in the treatment of a number of diseases, but not yet for bone and joint infections, even though these often require the expertise of several specialties. A newly established board for bone and joint infections in an university hospital showed an increasing number of requests from an increasing number of departments, showing a perceived need for interdisciplinary discussion of these often challenging cases. Board recommendations were mainly related to changes in antibiotic treatment and additional diagnostics, hinting at a potential impact of such discussion on individual treatment, while formal outcome evaluation is pending. 
Table 3 Characterization of patients with more than one focus of infection, categorization according to the leading infection focus ( $P P I$ periprosthetic infection)

Number of patients with more than one focus of infection

Bilateral joint infection (native knee infection and PPI)

Vertebral osteomyelitis AND

Shoulder empyema

Osteomyelitis of foot

Osteomyelitis of femur

Osteomyelitis of sternum AND sacrum

Empyema of shoulder AND soft tissue infection (M. psoas, M. pectoralis)

Hip empyema

Knee empyema

PPI of hip

PPI of knee

Periprosthetic infection of hip AND

\section{PPI of knee}

Suspected hip empyema

Osteomyelitis of foot AND

Empyema of shoulder

Osteomyelitis of symphyse AND

Soft tissue infection of symphyse

Osteomyelitis of tibia AND

Soft tissue infection of lower leg

Empyema of hip AND

Bilateral shoulder empyema AND soft tissue infection (back muscles)

Vertebral osteomyelitis AND abscesses (lung and muscles) AND suspected infection of thrombosis femoral

osteomyelitis of sternum

osteomyelitis of sternum AND mediastinitis

Empyema of knee AND

Suspected infection of spine

Soft tissue infection of knee

Osteomyelitis of shoulder AND osteomyelitis of clavicula AND soft tissue infections (abscess of lung, endophtalmitis, suspected septical 1 embolie)

Infection post-surgery (tibia) AND

Knee empyema

Infection post-surgery femur

Suspected infection of spine AND knee joint

Suspected infection of hip joint AND spine

Suspected infection of tibia AND femur

Foreign material infection of the spine AND

Septic herd encephalitis AND septic arthritis of both feet 


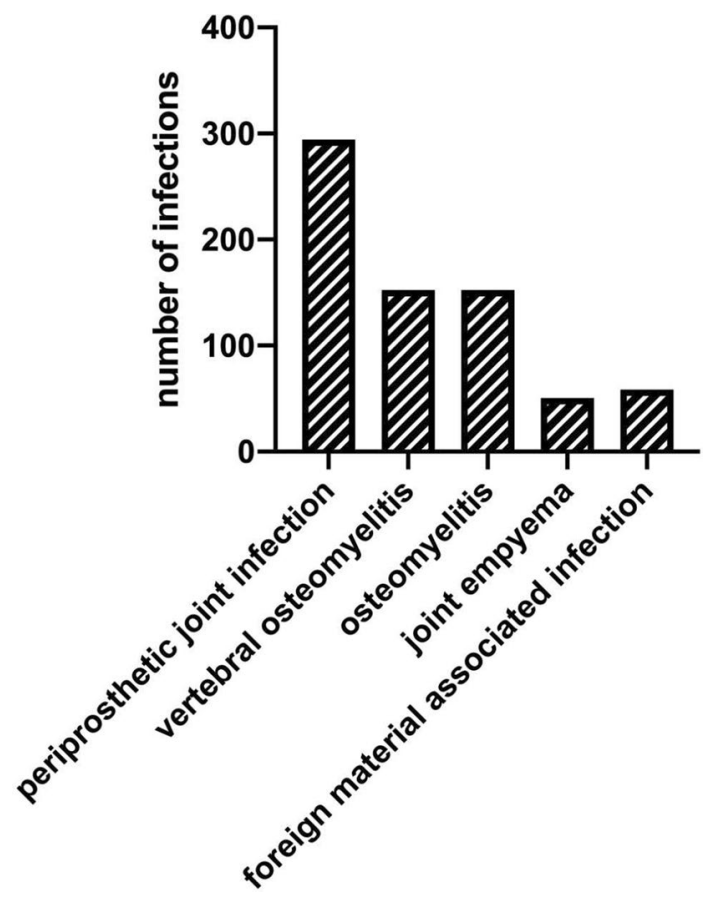

Fig. 3 Classification of the 706 bone- and joint-associated infections discussed at the OMB (OMB osteomyelitis board). Periprosthetic infections were counted as a separate entity, infections associated with internal plate and/or screw fixation were subsumed under "foreign material-associated infections"

Author contributions Conceptualization: COL, NJ. Methodology: COL, NJ. Formal analysis and investigation: COL. Writing-original draft preparation: COL. Writing-review and editing: NJ, KSH, CMS, AY, PE. Resources: PE, NJ. Supervision: PE.

Funding Open Access funding enabled and organized by Projekt DEAL. No funding/Not applicable.

Availability of data and material The original data are held by the corresponding author and can be viewed there at any time.

Code availability Not applicable.

\section{Declarations}

Conflict of interest There are no conflicts of interests or competing interests related to this work of the authors.

Ethics approval, Consent to participate/for publication The study was approved by the local ethics committee of the University Clinic of Cologne (vote 20-1137). In view of the retrospective nature of the study and all the procedures being performed were part of the routine care.

Open Access This article is licensed under a Creative Commons Attribution 4.0 International License, which permits use, sharing, adaptation, distribution and reproduction in any medium or format, as long as you give appropriate credit to the original author(s) and the source, provide a link to the Creative Commons licence, and indicate if changes were made. The images or other third party material in this article are included in the article's Creative Commons licence, unless indicated otherwise in a credit line to the material. If material is not included in the article's Creative Commons licence and your intended use is not permitted by statutory regulation or exceeds the permitted use, you will need to obtain permission directly from the copyright holder. To view a copy of this licence, visit http://creativecommons.org/licenses/by/4.0/.

\section{References}

1. Kremers HM, Nwojo ME, Ransom JE, Wood-Wentz CM, Melton LJ 3rd, Huddleston PM 3rd. Trends in the epidemiology of osteomyelitis: a population-based study, 1969 to 2009. J Bone Joint Surg Am. 2015;97(10):837-45.

2. Kurtz SM, Lau E, Watson H, Schmier JK, Parvizi J. Economic burden of periprosthetic joint infection in the United States. J Arthroplasty. 2012;27(8 Suppl):61-5.e1.

3. Tao Z, Shi A, Zhao J. Epidemiological Perspectives of Diabetes. Cell Biochem Biophys. 2015;73(1):181-5.

4. Statistisches Bundesamt. Bevölkerungsentwicklung bis 2060 Ergebnisse der 13. koordinierten Bevölkerungsvorausberechnung - Aktualisierte Rechnung auf Basis 2015. Accessed 2021 Apr 28. https://www.destatis.de/DE/Themen/Gesellschaft-Umwelt/Bevoe lkerung/Bevoelkerungsvorausberechnung/Publikationen/Downl oads-Vorausberechnung/bevoelkerung-bundeslaender-2060-aktua lisiert-5124207179004.html

5. Osmon DR, Berbari EF, Berendt AR, Lew D, Zimmerli W, Steckelberg JM, Rao N, Hansson A, Wilson WR, Infectious Diseases Society of America. Diagnosis and management of prosthetic joint infection: clinical practice guidelines by the Infectious Diseases Society of America. Clin Infect Dis. 2013;56(1):e1-e25.

6. Berbari EF, Kanj SS, Kowalski TJ, Darouiche RO, Widmer AF, Schmitt SK, Hendershot EF, Holmton PD, Huddleston 3rd PM, Petermann GW, Osmon DR, Infectious Diseases Society of America. 2015 Infectious Diseases Society of America (IDSA) Clinical Practice Guidelines for the Diagnosis and Treatment of Native Vertebral Osteomyelitis in Adults. Clin Infect Dis 2015;61(6):e26-46.

7. AWMF online. Akute und chronische exogene Osteomyelitis langer Röhrenknochen des Erwachsenen" - S2k-Leitlinie. Accessed 2021 Apr 28 https://www.awmf.org/uploads/tx_szlei tlinien/012-0331_S2k_Osteomyelitis_2018-01_1.pdf

8. AWMF online. Diagnostik und Therapie der SpondylodiszitisS2k-Leitlinie. Accessed 2021 Apr 28. https://www.awmf.org/ uploads/tx_szleitlinien/151-0011_S2k_Diagnostik-TherapieSpondylodiszitis_2020-10.pdf

9. American Academy of Orthopaedic Surgeons (AAOS) Diagnosis and Prevention of Periprosthetic Joint Infections - Clinical Practice Guideline. Published March 11, 2019. Accessed 2021 Apr 28. https://www.aaos.org/pjiguideline.

10. Esposito S, Leone S, Bassetti M, Borrè S, Leoncini F, Meani E, Venditti M, Mazzotta F Bone Joint Infections Committee fort he Italian Society of Infectious Tropical Dideases (SIMIT). Italian guidelines for the diagnosis and infectious disease management of osteomyelitis and prosthetic joint infections in adults. Infection. 2009;37(6):478-96.

11. International Consensus Group (Philadelphia Consensus), "Proceedings of the Second International Consensus Meeting on Musculosceletal Infection”, Accessed 2021 Apr 28 https://www.arthr oplastyjournal.org/issue/S0883-5403(18)X0012-6

12. Société de Pathologie Infectieuse de Langue Française (SPLIF), Collège des Universitaires de Maladies Infectieuses et Tropicales (CMIT), Groupe de Pathologie Infectieuse Pédiatrique (GPIP), Société Française d'Anesthésie et de Réanimation (SFAR), Société 
Française de Chirurgie Orthopédique et Traumatologique (SOFCOT), Société Française d'Hygiène Hospitalière (SFHH), Société Française de Médecine Nucléaire (SFMN), Société Française de Médecine Physique et de Réadaptation (SOFMER), Société Française de Microbiologie (SFM), Société Française de Radiologie (SFR-Rad), Société Française de Rhumatologie (SFR-Rhu). Recommendations for bone and joint prosthetic device infections in clinical practice (prosthesis, implants, osteosynthesis). Société de Pathologie Infectieuse de Langue Française. Med Mal Infect. 2010;40(4):185-211.

13. Kapadia BH, McElroy MJ, Issa K, Johnson AJ, Bozic KJ, Mont MA. The economic impact of periprosthetic infections following total knee arthroplasty at a specialized tertiary-care center. J Arthroplasty. 2014;29(5):929-32.

14. Specchia ML, Frisicale EM, Carini E, Di Pilla A, Cappa D, Barbara A, Ricciardi W, Damiani G. The impact of tumor board on cancer care: evidence from an umbrella review. BMC Health Serv Res. 2020;20(1):73.

15. OnkoZert. Erhebungsbogen Onkologisches Zentrum. Accessed 2021 Apr 28. https://www.onkozert.de/onkologische-zentren/

16. Camou F, Dijos M, Baradon L, Cornolle C, Greib C, Laine M, Recomte R, Boutoille D, Machelart I, Peuchant O, Tlili G, Wirth G, Issa N. Management of infective endocarditis and multidisciplinary approach. Med Mal Infect. 2019;49(1):17-22.

17. Roger P-M, Garo B, Roblot F, Bernard E. Implication of antibiotic referents in complex bone and joint infections. Med Mal Infect. 2013;43(4):159-62.

18. Grammatico-Guillon L, Baron S, Gaborit C, Rusch E, Astagneau P. Quality assessment of hospital discharge database for routine surveillance of hip and knee arthroplasty-related infections. Infect Control Hosp Epidemiol. 2014;35(06):646-51.

19. French Health Ministry. Instruction $N^{\circ}$ DGOS/PF2/2010/466 December 27th, 2010 on complex bone and joint infections care. Accessed 2017 Apr 27 http://socialsante.gouv.fr/IMG/pdf/instr uction_466_271210.pdf

20. Rieg S, Hitzenbichler F, Hagel S, Suarez I, Kron F, Salzberger B, Pletz M, Kern WV, Fätkenheuer G, Jung N. Infectious disease services: a survey from four university hospitals in Germany. Infection. 2019;47(1):27-33.

21. Kurtz SM, Ong KL, Lau E, Bozic KJ, Berry D, Parvizi J. Prosthetic joint infection risk after TKA in the Medicare population. Clin Orthop Relat Res. 2010;468(1):52-6.

22. Yokoe DS, Avery TR, Platt R, Huang SS. Reporting surgical site infections following total hip and knee arthroplasty: impact of limiting surveillance to the operative hospital. Clin Infect Dis. 2013;57(9):1282-8.
23. Kehrer M, Pedersen C, Jensen TG, Lassen AT. Increasing incidence of pyogenic spondylodiscitis: a 14-year population-based study. J Infect. 2014;68(4):313-20.

24. Akiyama T, Chikuda H, Yasunaga H, Horiguchi H, Fushimi K, Saita K. Incidence and risk factors for mortality of vertebral osteomyelitis: a retrospective analysis using the Japanese diagnosis procedure combination database. BMJ Open. 2013;3(3): e002412.

25. Hatzenbuehler J, Pulling TJ. Diagnosis and management of osteomyelitis. Am Fam Physician. 2011;84(9):1027-33.

26. Uckay I, Vernaz-Hegi N, Harbarth S, Stern R, Legout L, Vauthey L, Ferry T, Lübbeke A, Assal M, Lew D, Hoffmeyer P, Bernard L. Activity and impact on antibiotic use and costs of a dedicated infectious diseases consultant on a septic orthopaedic unit. J Infect. 2009;58(3):205-12.

27. Vogel M, Schmitz RPH, Hagel S, Pletz MW, Gagelmann N, Scherag A, Schlattmann P, Brunkhorst F. Infectious disease consultation for Staphylococcus aureus bacteremia - A systematic review and meta-analysis. J Infect. 2016;72(1):19-28.

28. Schmitt S, McQuillen DP, Nahass R, Martinelli L, Rubin M, Schwebke K, Petrak R, Ritter JT, Chansolme D, Slama T, Drozd EM, Braithwaite SF, Johnsrud M, Hammelman E. Infectious diseases specialty intervention is associated with decreased mortality and lower healthcare costs. Clin Infect Dis. 2014;58(1):22-8.

29. Fox BC, Imrey PB, Voights MB, Norwood S. Infectious disease consultation and microbiologic surveillance for intensive care unit trauma patients: a pilot study. Clin infect Dis. 2001;33(12):1981-9.

30. Hamandi B, Husain S, Humar A, Papadimitropoulos EA. Impact of infectious disease consultation on the clinical and economic outcomes of solid organ transplant recipients admitted for infectious complications. Clin Infect Dis. 2014;59(8):1074-82.

31. Rieg S, Küpper MF. Infectious diseases consultations can make the difference: a brief review and a plea for more infectious diseases specialists in Germany. Infection. 2016;44(2):159-66.

32. Forsblom E, Ruotsalainen E, Ollgren J, Järvinen A. Telephone consultation cannot replace bedside infectious disease consultation in the management of Staphylococcus aureus Bacteremia. Clin Infect Dis. 2013;56(4):527-35.

33. Ntalos D, Schoof B, Thiesen DM, Viezens L, Kleinertz H, Rohde H, Both A, Luebke A, Strahl A, Dreimann M, Stangenberg M. Implementation of a multidisciplinary infections conference improves the treatment of spondylodiscitis. Sci Rep. 2021;11(1):9515. 